\title{
Comparison of Short-Term Clinical and Electrophysiological Outcomes of Local Steroid Injection and Surgical Decompression in the Treatment of Carpal Tunnel Syndrome
}

\author{
Ahmet Gurhan GURCAY ${ }^{1}$, Ozgur Zeliha KARAAHMET ${ }^{2}$, Oktay GURCAN ${ }^{1}$, Atilla KAZANCI ${ }^{1}$, Pinar Bora KARSLI ${ }^{2}$, \\ Ebru Karaca UMAY², Sevtap ACER ${ }^{2}$, Ece UNLU², Aytul $\mathrm{CAKCl}^{2}$
}

${ }^{1}$ Atatürk Education and Research Hospital, Department of Neurosurgery, Ankara, Turkey

${ }^{2}$ Diskapi Yildirim Beyazit Education and Research Hospital, Department of Physical Medicine and Rehabilitation, Ankara, Turkey

\section{ABSTRACT}

AIM: To investigate the effectiveness of local steroid injection and surgical decompression in the treatment of patients with severe carpal tunnel syndrome (CTS) and also to compare short-term outcomes using clinical and electrophysiological criteria.

MATERIAL and METHODS: The patients diagnosed as severe CTS were divided into two groups. Group 1 received local steroid injection and Group 2 underwent surgical decompression. The Boston Questionnaire that consists of two sections as the Boston Symptom Severity Scale (BSS) and the Functional Status Scale (FSS) was completed by the patients.

RESULTS: A total of 33 patients completed the study. Since two patients had bilateral severe CTS, a total of 35 hands were evaluated in the study. In Group 1, a significant difference was recorded between some pre- and post-treatment clinical parameters (BSS and FSS scores) and all electrophysiological parameters excluding motor conduction velocities. In Group 2, a statistically significant difference was found between pre- and post-treatment BSS scores and all electrophysiological parameters excluding motor conduction velocity and distal latency. However intergroup differences were not statistically significant as for all clinical and electrophysiological parameters (BSS, FSS, sensory amplitude, sensory conduction velocity, distal latency, motor amplitude, motor conduction velocity).

CONCLUSION: In the treatment of severe CTS, steroid injection and surgical decompression achieved favourable improvements in clinical and electrophysiological parameters within a short-term without superiority of one treatment over other. Therefore, in patients in whom surgical decompression can not be applied, local steroid injection can be recommended as a less invasive and a promising treatment alternative.

KEYWORDS: Carpal tunnel syndrome, Function, Steroid injection, Surgical decompression, Symptom

\section{INTRODUCTION}

A Ithough numerous diseases have been implicated as the cause of carpal tunnel syndrome (CTS), most of them are idiopathic (9). Although the pathophysiology of CTS has not been completely elucidated yet, injury of the median nerve as a result of mechanical compression and ischemia has been emphasized. Combination of ischemic changes and prolonged mechanical pressure causes changes in the myelin sheath (28). Changes in intraneural microcirculation, impairment of axonal transport and alterations in vascular permeability have been detected. All of these cause edema formation and impairment of signal conduction (26).

The objective of the treatment is to relieve the pressure imposed on the median nerve. To this end, many conservative 
and surgical treatment modalities have been used (9). Local steroid injection and surgical decompression have been compared in numerous studies. Based on the level of evidence for mild to moderate CTS, local steroid injection, while for moderate to severe CTS surgical decompression has been recommended $(12,13,19)$.

Even though surgical decompression has been recommended for cases with severe CTS based on electrophysiological criteria; in a review, it has been emphasized that in the United Kingdom, incidence of surgery increased markedly at every 10 years and long-term effectiveness of steroid injections used as a first-line treatment has not been demonstrated $(15,22)$. The difference of this study from other studies is inclusion of patients with severe CTS in the study and evaluation of nonoperable patients as for the effects of local steroid injections.

In this study, we aimed to investigate the effectiveness of local steroid injection and surgical decompression in the treatment of patients with severe CTS and also to compare short-term outcomes using clinical and electrophysiological criteria.

\section{MATERIAL and METHODS}

The patients who presented to the outpatient clinics of Physical Therapy and Rehabilitation, and Neurosurgery, and were electrophysiologically diagnosed as severe CTS were included in the study. The study protocol was explained to all patients included in the study and their informed consent was obtained. Approval from the ethics committee was obtained and all procedures were performed in compliance with the Helsinki Declaration (29).

Patients with systemic diseases such as inflammatory rheumatoid disease, diabetes mellitus, hypothyroidism and those with a history of CTS surgery or peripheral nerve lesion of the forearm were excluded from the study. In the initial evaluation, age, gender, dominant hand, affected by CTS and basic symptoms of CTS (numbness, pain, awkwardness-weakness, paraesthesia and pain that awakened the patient at night) and duration of these symptoms and alleviating factors were recorded. Severity of pain was evaluated using the visual analogue scale (VAS) $(14,16)$.

The patients were divided into two groups. Group 1 received local steroid injection and Group 2 underwent surgical decompression. Patients who rejected surgical treatment were given injections. Patients determined their preferred treatment alternative.

Monitorization of all patients included in the study was based on clinical and electrophysiological examinations. The same person, using the Boston Questionnaire before and one month after the treatment, evaluated their clinical parameters. Bilateral electrophysiological examinations were performed by the same person before and one month after the treatment in the electromyography (EMG) laboratory.

Boston Questionnaire: This questionnaire form developed by Levine et al. in 1993 is completed by the patient $(6,17)$. It consists of two sections as the Boston Symptom Severity Scale (BSS) and the Functional Status Scale (FSS) items. BSS includes 11 and FSS 8 sections. Every section contains five separate responses; each response is graded from 1 to 5 points.

The mean score is calculated separately for BSS and FSS and it is obtained by dividing the total score with the number of questions. The validity and reliability of the Turkish version of the questionnaire has been confirmed (25). Its use in the evaluation of treatment effectiveness has been advised (10).

Electrophysiological Analysis: The Medelec Synergy 10 channel (Oxford, UK) EMG device was used. During nerve conduction studies for the diagnostic and follow-up parameters of CTS, median motor nerve distal latency, median motor nerve conduction velocity, median nerve compound muscle action potential (CMAP) amplitude at the wrist level, amplitudes of median nerve sensory conduction velocity over second digit-wrist segment, and median nerve sensory action potential over second digit-wrist segment amplitude were measured. In line with the prolongation of motor and sensory latencies, inability to elicit sensory action potentials or CMAP with lower amplitude or inability to induce CMAP, observation of frequent fibrillations, rarefactions of contraction waves and alterations in motor unit potentials on needle EMG were considered severe CTS (23).

Steroid Injection: While the patient was sitting erect, his affected arm was placed on the table with his/her wrist at extension. Following negative aspiration, a $22 \mathrm{G}$ needle was inserted at 60 degree to the skin surface into volar aspect of the wrist between tendons of palmaris longus and flexor carpi radialis, directed distally from the proximal wrist line and then $1 \mathrm{ml}$ of betamethasone phosphate $(2 \mathrm{mg}) /$ betamethasone dipropionate (5 mg) (Diprospan ${ }^{\circledR}$, Eczacibasi, Turkey) was injected into the carpal tunnel (27). Injections were performed by the same person (Figure 1).

Surgical Decompression: The patients were operated in the supine position with their affected arm and forearm at $90^{\circ}$ abduction on a sleeve board. Local anaesthesia was achieved with $6 \mathrm{cc}$ local anaesthetic (lidocaine $\mathrm{HCl}, 20 \mathrm{mg} / \mathrm{mL}$; epinephrine $\mathrm{HCl}, 0.0125 \mathrm{mg} / \mathrm{mL}$ ) (Jetocain ${ }^{\circledR}$, Adeka, Samsun, Turkey) infiltration. On the palmar aspect of the affected wrist, a $2.5 \mathrm{~cm}$ long skin incision was made from nearly $1.5 \mathrm{~cm}$ distal to the wrist line up to the ring finger. Through this incision, the palmar aponeurosis and subcutaneous fat tissues were peeled off with sharp dissection and the distal end of the transverse ligament was freed using a dissector. Then this ligament was cut longitudinally from the distal to proximal to expose the median nerve (Figure 2). Following hemostasis, the subcutaneous layers were closed with 4/0 Vicryl (polyglactin 910) sutures and the skin with $4 / 0$ prolene mattress sutures (14). The median duration of surgery was 18 minutes and blood loss was less than $5 \mathrm{cc}$. Daily wound dressings were performed and sutures were removed on the postoperative $10^{\text {th }}$ days.

Statistical Analysis: Data were analyzed using the IBM Statistical Package for Social Sciences v20 (SPSS Inc., Chicago, IL, USA). Normal distribution of the quantitative data was checked using the Shapiro-Wilk test. Yates' chi-squared 


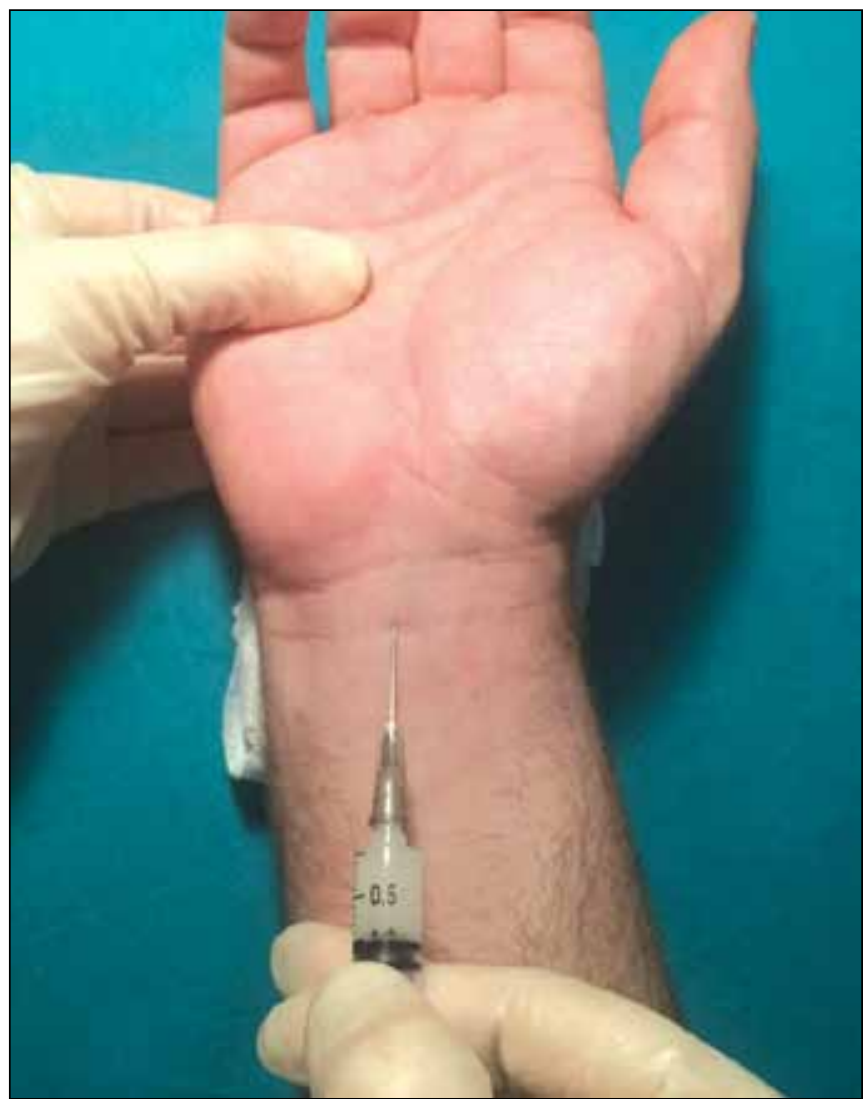

Figure 1: Local steroid injection.

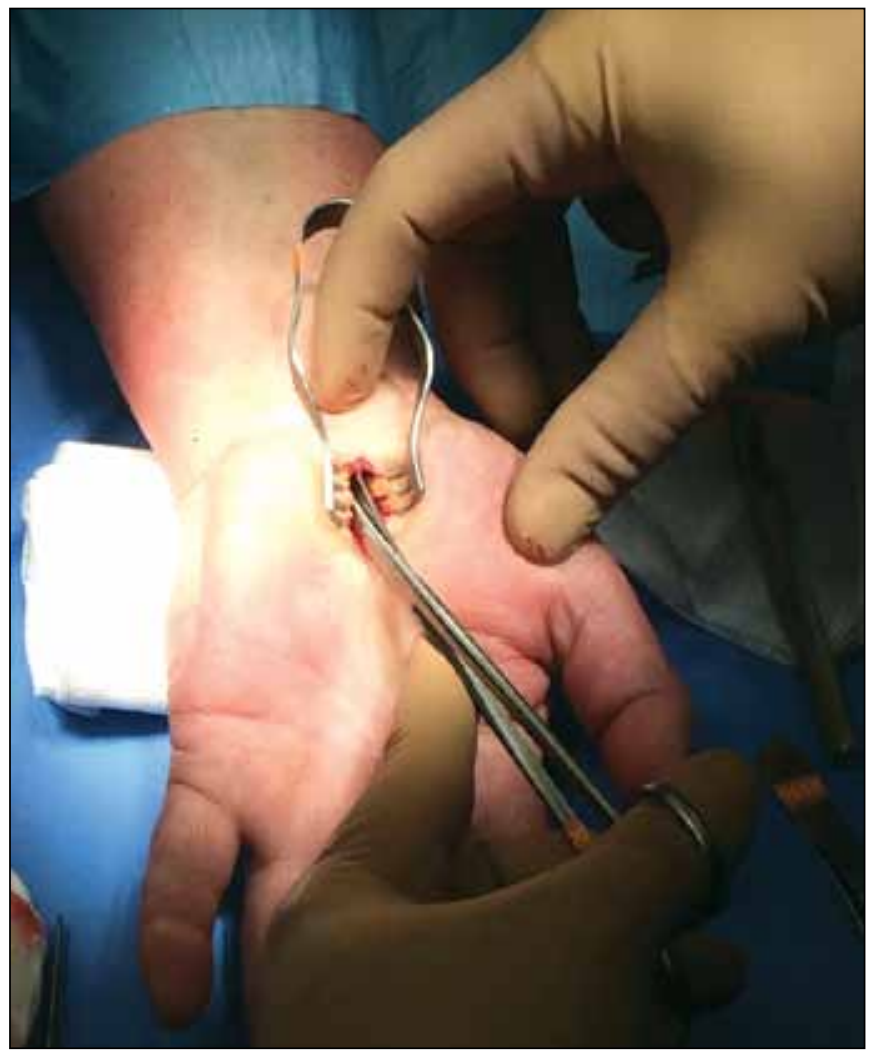

Figure 2: Surgical decompression. and Fisher's Exact tests were used to reveal whether there was a statistically significant change in the qualitative variables within the groups. The Mann-Whitney $U$ and Student's t-test were used to reveal whether there was a statistically significant difference in numerical variables within the groups. Paired Samples $T$ and Wilcoxon tests were used to reveal whether there was a statistically significant difference in the change of numerical variables within the groups. The results for all items were expressed as mean \pm SD, assessed within a $95 \%$ reliance and at a level of $\mathrm{p}<0.05$ significance.

\section{RESULTS}

A total of 39 patients were enrolled in the study. Four patients from the injection and 2 patients from the decompression groups were lost to follow-up, while a total of 33 patients completed the study. Since two patients had bilateral severe CTS, a total of 35 hands were evaluated in the study. Demographic and clinical data of the patients who completed the study are presented in Table I. In follow-ups performed one month after the treatment, no complication was encountered. A statistically significant difference was not detected between groups as for pain, weakness, awkwardness and presence of pain alleviating factors $(p=0.519, p=0.585, p=0.242$ and $\mathrm{p}=0.243$, respectively). In the injection group, dominant $(n=10$ patients), non-dominant $(n=5)$ hands or both hands $(n=2)$ were affected. In the surgical decompression group, 9 dominant and 7 non-dominant hands were affected. The functional status of the hands, which were not severely affected by CTS, and hands not included in the study are presented in Table II.

In the steroid injection therapy group, a significant difference was recorded between some pre- and post-treatment clinical parameters (BSS and FSS scores) and all electrophysiological parameters excluding motor conduction velocities (Table III). In the surgical decompression group, a statistically significant difference was found between pre and post-treatment BSS scores and all electrophysiological parameters excluding motor conduction velocity and distal latency (Table IV). However intergroup differences were not statistically significant as for all clinical and electrophysiological parameters (BSS, FSS, sensory amplitude, sensory conduction velocity, distal latency, motor amplitude, motor conduction velocity) $(p=0.212$, $\mathrm{p}=0.156, \mathrm{p}=0.289, \mathrm{p}=0.829, \mathrm{p}=0.178, \mathrm{p}=0.51$ and $\mathrm{p}=0.122$, respectively).

Post-treatment EMGs of the patients were evaluated in two groups as normal and CTS. Accordingly, complete improvement based on electrophysiological criteria was not detected in the two treatment groups. However, in the injection and surgery groups, normalization of sensory conduction velocities ( $n=0$ vs. 1 ), sensory amplitude $(n=9$ vs. 4), distal latency ( $n=3$ vs. 0$)$, and motor amplitude $(n=7$ vs. 3 ) was detected in the corresponding number of patients. No statistically significant intergroup difference was detected $(p=0.457, p=0.293, p=0.234$ and $p=0.285$, respectively).

\section{DISCUSSION}

Treatment of CTS is one of the most frequently investigated 
Table I: Demographic and Clinical Characteristics of the Patients

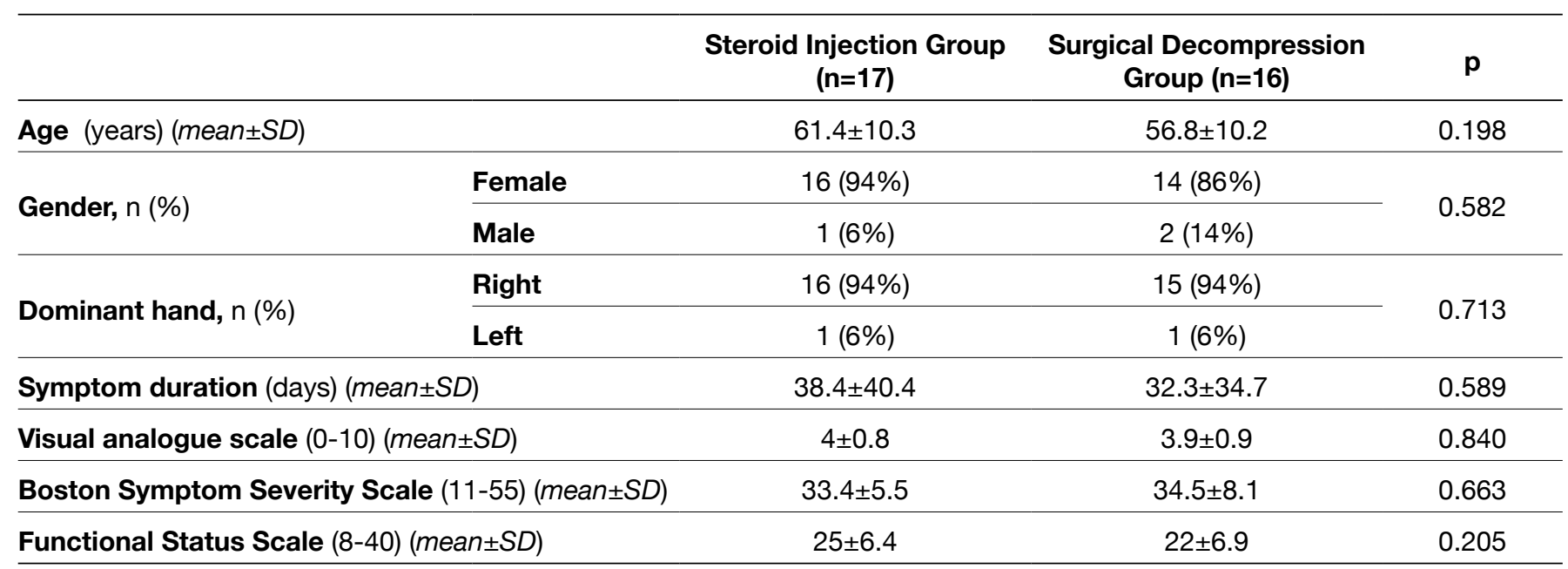

SD: Standard deviation.

Table II: The Functional State of the Patients' Hands without Severe Carpal Tunnel Syndrome, which were not Included in the Study

\begin{tabular}{lcc}
\hline $\begin{array}{l}\text { Carpal tunnel } \\
\text { syndrome }\end{array}$ & $\begin{array}{c}\text { Steroid Injection } \\
\text { Group (n=17) }\end{array}$ & $\begin{array}{c}\text { Surgical } \\
\text { Decompression } \\
\text { Group (n=16) }\end{array}$ \\
\hline Absent, $\mathrm{n}(\%)$ & $4(23 \%)$ & $4(25 \%)$ \\
\hline Mild, $\mathrm{n}(\%)$ & $4(23 \%)$ & $2(12 \%)$ \\
\hline Moderate, $\mathrm{n}(\%)$ & $7(42 \%)$ & $10(63 \%)$ \\
\hline
\end{tabular}

issues. Treatment methods can be generally divided as conservative therapy and surgical decompression. Many studies have investigated effectiveness of local steroid injections among conservative methods. The outcomes are still controversial and a definitive consensus has not been arrived at. Parameters to be followed up, injection methods, formulations and doses of the steroids used differ among these studies. In our study, we aimed to investigate the effectiveness of local steroid injections and surgical decompression in the treatment of the patients with severe CTS and also to compare their short-term results based on clinical and electrophysiological criteria. We noted favourable posttreatment improvements in all clinical and electrophysiological parameters (excl. motor conduction velocities) when we evaluated severity of symptoms and functional status in the steroid injection group. Gelbermen et al., Gurcay et al. and Yagcl et al. achieved successful outcomes with local corticosteroid injections in patients with CTS who had mild to moderate symptoms $(6,8,30)$. In their randomized, double-blind, placebo-controlled study, Dammers et al. compared 40mg methyl prednisolone and $10 \mathrm{mg}$ lidocaine injections and reported improvement rates at 1 month as 77 and $20 \%$, respectively (4). They also stated that effectiveness of steroid injections decreased at $1^{\text {st }}$ year, whereas owing to favourable outcomes of steroid injections they recommended that steroid injection therapy should be considered as a treatment alternative before surgery. Girlanda et al. injected $15 \mathrm{mg}$ prednisolone into 27 and saline into 26 hands (7). They reported failure to obtain favourable responses in only $8 \%$ of the hands in the short term while at $6^{\text {th }}$ and $18^{\text {th }}$ months, the functional status of 50 and $90 \%$ of the previously responsive hands had worsened, respectively. Agarwal et al. applied single doses of local steroid injections in 48 patients and reported significant improvements in $93.7 \%$ of the patients (1). However, among them, symptoms had recurred in 8 patients at $1^{\text {st }}$ year, while in $79 \%$ of the patients symptomatic regression continued at the end of the first year. In a study performed in Netherlands, the improvement rate at the end of the first year of injectable steroid therapy was reported as $25 \%$ (2). Similarly Meys et al. emphasized the need for surgery in $67 \%$ of the patients at the end of the first year of injectable steroid therapy (20). A consensus has not been reached about treatment with recurrent steroid injections. Phalen et al. indicated possible preoperative application of injectable steroid therapy for 3 times (24).

Mondelli et al. evaluated the correlation between Boston scale scores and electrophysiological findings in the monitorization of the patients with CTS treated with surgery and detected marked improvements in Boston scale scores, distal motor and sensory conduction velocities at both the $1^{\text {st }}$ and $6^{\text {th }}$ months (21). Similarly, in our study, in the surgical decompression group, favourable developments were detected in BSS scores among clinical parameters and all other electrophysiological parameters excluding motor velocities and distal latency. Bland et al. emphasized that surgical decompression is quite effective in many patients with variable success rates. They also stressed that erroneous diagnosis, surgical malpractice and incomplete decompression are important causes of failure. In a meta-analysis, which analyzed 209 studies, an improvement rate of $75 \%$ was reported in 32,036 operations (3). 
Table III: Comparison of Pre- and Post-Treatment Clinical and Electrophysiological Parameters in the Steroid Injection Group

\begin{tabular}{lccc}
\hline Parameters & $\begin{array}{c}\text { Before treatment } \\
\text { mean } \pm \text { SD }\end{array}$ & $\begin{array}{c}\text { After treatment } \\
\text { mean } \pm \text { SD }\end{array}$ & p \\
\hline Boston Symptom Severity Scale $(11-55)($ mean $\pm S D)$ & $33.4 \pm 5.5$ & $25.3 \pm 8.3$ & $\mathbf{0 . 0 0 0}$ \\
\hline Functional Status Scale $(8-40)($ mean $\pm S D)$ & $25 \pm 6.4$ & $19.7 \pm 6.6$ & $\mathbf{0 . 0 0 1}$ \\
\hline Sensory amplitude & $6 \pm 7.1$ & $18 \pm 13$ & $\mathbf{0 . 0 0 2}$ \\
\hline Sensory conduction velocity & $13.9 \pm 14$ & $27.2 \pm 8$ & $\mathbf{0 . 0 0 1}$ \\
\hline Distal latency & $6.2 \pm 1.2$ & $4.9 \pm 1.4$ & $\mathbf{0 . 0 0 0}$ \\
\hline Motor amplitude & $4 \pm 1.6$ & $5.7 \pm 1.8$ & $\mathbf{0 . 0 0 1}$ \\
\hline Motor conduction velocity & $52.1 \pm 5$ & $52.6 \pm 4.7$ & 0.340 \\
\hline
\end{tabular}

SD: Standard deviation.

Table IV: Comparison of Pre- and Post-Treatment Clinical and Electrophysiological Parameters in the Surgical Decompression Group

\begin{tabular}{lccc}
\hline Parameters & $\begin{array}{c}\text { Before treatment } \\
\text { mean } \pm \text { SD }\end{array}$ & $\begin{array}{c}\text { After treatment } \\
\text { mean } \pm \text { SD }\end{array}$ & p \\
\hline Boston Symptom Severity Scale $(11-55)($ mean $\pm S D)$ & $34.5 \pm 8.1$ & $29.3 \pm 7.9$ & $\mathbf{0 . 0 1}$ \\
\hline Functional Status Scale $(8-40)($ mean $\pm S D)$ & $22 \pm 6.9$ & $20 \pm 8.4$ & 0.242 \\
\hline Sensory amplitude & $4.9 \pm 9$ & $13.5 \pm 13$ & $\mathbf{0 . 0 0 1}$ \\
\hline Sensory conduction velocity & $9.7 \pm 11.5$ & $23.5 \pm 11$ & $\mathbf{0 . 0 0 4}$ \\
\hline Distal latency & $7 \pm 2.8$ & $6.8 \pm 1.6$ & 0.684 \\
\hline Motor amplitude & $2.7 \pm 2.1$ & $3.4 \pm 2.1$ & $\mathbf{0 . 0 1}$ \\
\hline Motor conduction velocity & $43.4 \pm 13$ & $48.6 \pm 6.6$ & 0.120 \\
\hline
\end{tabular}

SD: Standard deviation.

In our study, both steroid injection and surgical decompression treatments were found to be effective but neither one of them was superior to the other in the short term. Yağci et al. compared local corticosteroid injection and surgical decompression and they indicated equivalent effectiveness for injection and surgical decompression therapies based on 3-month-outcomes (30). Demirci et al. reported that worse outcomes had been obtained in the injection group at 6 months while local steroid therapy had transient effectiveness (5). Hui et al. compared surgical decompression and steroid injection in their single-blind, randomized controlled study and reported that surgical decompression achieved better clinical improvement at the end of the $20^{\text {th }}$ week; however, injection therapy was found to be more successful for grip strength (11). In a similar study, Ly-pen et al. also compared steroid injection and surgical decompression and found response rates in the injection and surgical decompression groups at $3^{\text {rd }}, 6^{\text {th }}$ and $12^{\text {th }}$ months as. 94 vs. $75 \% ; 85.5$ vs. $76.3 \%$, and 69.9 vs. $75 \%$, respectively (18). The authors indicated that local steroid injections had provided better symptomatic improvement in the short-term, while it was as effective as surgical decompression in the $1^{\text {st }}$ year of the treatment.
Despite controversial outcomes in the literature, local steroid injections have been thought to provide as effective symptomatic improvement as surgical methods at least in the short term. Also in our study, local steroid injection was found to be as successful as surgical decompression, which is in accordance with short-term outcomes reported in the literature $(5,18,30)$.

\section{CONCLUSION}

In the treatment of severe CTS, steroid injection and surgical decompression achieved favourable improvements in clinical and electrophysiological parameters within a short term without superiority of one treatment over the other. Therefore, in patients in whom surgical decompression can not be applied, local steroid injection can be recommended as a less invasive and a promising treatment alternative.

\section{ACKNOWLEDGEMENTS}

The English in this document has been checked by at least two professional editors, both native speakers of English. 


\section{- REFERENCES}

1. Agarwal V, Singh R, Sachdev A, Wiclaff, Shekhar S, Goel D: A prospective study of the long-term efficacy of local methyl prednisolone acetate injection in the management of mild carpal tunnel syndrome. Rheumatol (Oxford) 44:647-650, 2005

2. Berger $M$, Vermeulen $M$, Koelman $J H$, van Schaik IN, Roos YB: The long-term follow-up of treatment with corticosteroid injections in patients with carpal tunnel syndrome. When are multiple injections indicated? J Hand Surg Eur 38:634-639, 2013

3. Bland JD: Treatment of carpal tunnel syndrome. Muscle Nerve 36: 167-171, 2007

4. Dammers JW, Veering MM, Vermeulen M: Injection with methylprednisolone proximal to the carpal tunnel: Randomised double-blind trial. BMJ 319: 884-886, 1996

5. Demirci S, Kutluhan S, Koyuncuoglu HR, Kerman M, Heybeli N, Akkus S, Akhan G: Comparison of open carpal tunnel release and local steroid treatment outcomes in idiopathic carpal tunnel syndrome. Rheumatol Int 22:33-37, 2002

6. Gelbermen R, Aranson D, Weisman M: Carpal Tunnel Syndrome. J Bone and Joint Surg 62: 1181-1184, 1980

7. Girlanda P, Dattola R, Venuto C, Mangiapane R, Nicolosi C, Messina C: Local steroid treatment in idiopathic carpal tunnel syndrome: Short- and long-term efficacy. J Neurol 240:187190, 1993

8. Gurcay E, Unlu E, Bal A, Gurçay AG, Aydog E, Cakci A: Karpal tunel sendromunun tedavisinde iyontoforez, lokal kortikosteroid enjeksiyon ve non-steroid anti-inflamatuar ilaç etkinliğinin karșılaştırılması. Fırat Tıp Dergisi 13:39-42, 2008 (Article in Turkish)

9. Hadler NM: Nerve entrapment syndromes. In: Mc Carty DJ, Kopman WJ (eds), Arthritis and Allied Conditions. Philadelphia: Lea and Febiger, 1993:1619-1624

10. Heybeli N, Kutluhan S, Demirci S, Kerman M, Mumcu EF: Assessment of outcome of carpal tunnel syndrome: A comparison of electrophysiological findings and a selfadministered Boston questionnaire. J Hand Surg Br 27:259264, 2002

11. Hui AC, Wong S, Leung CH, Tong P, Mok V, Poon D, Li-Tsang CW, Wong LK, Boet R: A randomized controlled trial of surgery vs steroid injection for carpal tunnel syndrome. Neurology 64 : 2074-2078, 2005

12. Huisstede BM, Hoogvliet P, Randsdorp MS, Glerum S, van Middelkoop M, Koes BW: Carpal tunnel syndrome. Part I: Effectiveness of nonsurgical treatments-a systematic review. Arch Phys Med Rehabil 91: 981-1004, 2010

13. Huisstede BM, Randsdorp MS, Coert JH, Glerum S, van Middelkoop M, Koes BW: Carpal tunnel syndrome. Part II: Effectiveness of surgical treatments-a systematic review. Arch Phys Med Rehabil 91: 1005-1024, 2010

14. lida J, Hirabayashi $H$, Nakase $H$, Sakaki T: Carpal tunnel syndrome: Electrophysiological grading and surgical results by minimum incision open carpal tunnel release. Neurol Med Chir (Tokyo) 48:554-559, 2008

15. Jerosch-Herold C, Shepstone L, Wilson ECF, Dyer T, Blake $\mathrm{J}$ : Clinical course, costs and predictive factors for response to treatment in carpal tunnel syndrome: The PALMS study protocol. BMC Musculoskelet Disord 15:35, 2014

16. Kersten $P$, Küçükdeveci $A A$, Tennant $A$ : The use of the Visual Analogue Scale (VAS) in rehabilitation outcomes. J Rehabil Med 44: 609-610, 2012

17. Levine DW, Sõmmons B, Korõs MJ, Daltroy LH, Hohl GG, Fossel AN, Katz JN: A self-administered questionnaire for the assessment of severity of symptoms and functional status in carpal tunnel syndrome. J Bone Joint Surg Am 75:1585-1592, 1993

18. Ly-Pen D, Andreu JL, de Blas G, Sanchez-Olaso A, Millan I: Surgical decompression versus local steroid injection in carpal tunnel syndrome: A one-year, prospective, randomized, open, controlled clinical trial. Arthritis Rheum 52: 612-619, 2005

19. Marshall SC, Tardif G, Ashworth NL: Local corticosteroid injection for carpal tunnel syndrome. Cochrane Database Syst Rev 18(2):CD001554, 2007

20. Meys V, Thissen S, Rozeman S, Beekman R: Prognostic factors in carpal tunnel syndrome treated with a corticosteroid injection. Muscle Nerve 44:763-768, 2011

21. Mondelli M, Reale F, Sicurelli F, Padua L: Relationship between the self-administered Boston questionnaire and electrophysiological findings in follow-up surgically-treated carpal tunnel syndrome. J Hand Surg Br 25:128-134, 2000

22. Nadler SF, Nadler JS: Cumulative trauma disorders. In: DeLisa JA, Gans BM (eds), Rehabilitation Medicine Principles and Practise, $3^{\text {rd }}$ ed. Philadelphia: Lippincott Williams\&Wilkins, 1998:1661-1676

23. Oh SJ: Normal values for common nerve conduction tests. In: Oh SJ (ed), Clinical Electromyography. Nerve Conduction Studies. $2^{\text {nd }}$ ed. Baltimore, Maryland: Williams \& Wilkins, 1993: 84-105

24. Phalen GS: The carpal tunnel syndrome: Clinical evaluation of 598 hands. Clin Orthop Relat Res 83: 29-40, 1972

25. Sezgin M, Incel NA, Serhan S, Camdeviren H, As I, Erdoğan C: Assessment of symptom severity and functional status in patients with carpal tunnel syndrome: Reliability and functionality of the Turkish version of the Boston Questionnaire. Disabil Rehabil 28: 1281-1285, 2006

26. Thomas MA, Fast A, Bach JR: Rehabilitation of the patient with diseases of the motor unit. In: DeLisa JA, Gans BM (eds), Rehabilitation Medicine Principles and Practise, $3^{\text {rd }}$ ed. Philadelphia: Lippincott Williams\&Wilkins, 1998:1545-1574

27. Tüzün F: Lokal enjeksiyonlar. In: Beyazova M, Kutsal YG (eds), Fiziksel Tıp ve Rehabilitasyon. Ankara: Güneş Kitabevi Ltd., 2000:738-747 (In Turkish)

28. Werner RA, Andary M: Carpal tunnel syndrome: Pathophysiology and clinical neurophysiology. Clin Neurophysiol 113: 1373-1381, 2002

29. World Medical Association General Assembly: World Medical Association Declaration of Helsinki: Ethical principles for medical research involving human subjects. J Int Bioethique 15: 124-129, 2004

30. Yağcı I, Ucan H, Yılmaz L, Yağmurlu F, Keskin D, Bodur H: Karpal tunel sendromu tedavisinde splint, splint ile lokal steroid enjeksiyonu ve cerrahinin karşılaştırılması. Türk Fiz Tıp Rehab Derg 52: 55-60, 2006 (In Turkish) 